\title{
WORKSHOP DE TREINAMENTO EM VIDEOAULAS: MODIFICAÇÕES A PARTIR DAS REPRESENTAÇÕES SOCIAIS DO GRUPO DE PROFESSORES-ALUNOS DO CEDERJ.
}

\author{
RIO DE JANEIRO/RJ JULHO/2018

\begin{abstract}
Wanessa do Bomfim Machado - CECIERJ/UFRJ - wanessamachado@yahoo.com.br
Mario Gandra - UFRJ - mariogandra@gmail.com

Denize Cristina de Oliveira - UERJ - dcouerj@gmail.com

Alexandre Farbiarz - UFF - alexandre.farbiarz@gmail.com
\end{abstract} \\ Tipo: Relato de Experiência Inovadora (EI) \\ Categoria: Conteúdos e Habilidades \\ Setor Educacional: EDUCAÇÃO SUPERIOR
}

\begin{abstract}
RESUMO
A educação a distância (EAD) exige novas competências do professor. Nesse contexto, insere-se a pesquisa realizada junto a CECIERJ, responsável pela EAD superior no estado RJ. Com a demanda de maior midiatização, os docentes foram convocados a gravarem videoaulas, mas a adesão foi irrisória. Assim, uma pergunta que surge é: O que leva professores a não desejarem serem filmados em uma atividade cotidiana do fazer docente? Conhecer as representações sociais do professor é um aspecto fundamental no aprofundamento de questões voltadas para a prática ou identidade docente. Para tal, realizamos uma pesquisa do tipo explicativo, a partir de estudo quali-quantitativo, tendo-se por base a abordagem estrutural da TRS. Por meio de um questionário aberto aplicados aos professores-alunos de um workshop de formação em videoaulas apreendeu-se as motivações e expectativas dos professores inscritos. Como resultados principais, o baixo foco no aluno enquanto motivação e a grande intensidade nas expectativas negativas, mais frequentes que as positivas. Além disso, procedeu-se a um Teste de Evocação Livre com 130 professores do CEDERJ cujo termo indutor era "videoaula". Feita a análise prototípica e interpretando-se os dados com base na Teoria do Núcleo Central, chegou-se aos elementos estruturais das representações sociais desses professores. Estes resultados, com destaque para as cognições interação, tecnologia, ferramenta, modernidade e preparação como possíveis elementos do núcleo central indicam diferentes dimensões das RS. Juntamente com as cognições periféricas e resultados correlatos feitos por análise de conteúdo, aferiuse os pontos de atenção que devem ser focados seja na reestruturação do workshop, seja nas estratégias de captação dos professores.
\end{abstract}

Palavras-chave: educação a distância, videoaula, representações sociais, formação continuada, professor-ator

AGRADECIMENTOS

À PRESIDÊNCIA, VICE, CHEFIA E COLEGAS DA FUNDAÇÃO CECIERJ (2015-2018). AOS COORDENADORES DE CURSO E DISCIPLINA DO CONSÓRCIO CEDERJ. PRINCIPALMENTE, AOS PARTICIPANTES DO WORKSHOP VIDEOAULA CEDERJ. 


\section{INTRODUÇÃO}

A Fundação Cecierj através do Consórcio CEDERJ, viabiliza a educação pública superior a distância no RJ e tem investido no uso de videoaulas. O interesse dos professores neste recurso educacional, entretanto, foi insignificante. Em 2015, apenas $11,93 \%$ dos professores gravaram suas videoaulas. Como fomentar, então, um aumento de demanda?

A pista para tal investigação reside no fato de que, ao ser gravado, não é mais o mesmo professor que se faz ali presente. O contexto em EAD transforma a aula. E o professor encontra-se num outro patamar. Sua identidade enquanto docente parece sofrer alterações. Como entender e contornar essa questão?

Perrenoud (1999) afirma que não basta o (re)lançamento de programas de reforma da educação. É necessária uma mudança das "atitudes, representações e das identidades" dos atores. É, portanto, fundamental conhecer as representações sociais (RS) que os professores tem de videoaula.

Dessa forma, investigou-se as RS que esses professores tem sobre a videoaula, buscando-se ações que pudessem de forma prática trabalhar com essas RS. Como estratégia principal, a reformulação de um workshop para o treinamento dos professores.

\section{OBJETIVOS}

Investigar as RS que os professores tem sobre a videoaula e a partir desses resultados, formatar um novo modelo de workshop de treinamento em videoaula.

\section{REFERENCIAL TEÓRICO}

\subsection{Teoria das Representações Sociais}

A Teoria das Representações Sociais (TRS) é fundada em 1961, por Serge Moscovici. Para ele, uma representação é sempre de alguém em relação a alguma coisa, um objeto (real ou imaginário). Mas esse alguém está sempre inserido num ou em vários grupos.

Para Denise Jodelet (2001, p. 22), as RS são "uma forma de conhecimento socialmente elaborada e compartilhada, com um objetivo prático, e que contribui para a construção de uma realidade comum a um conjunto social". Segundo Moscovici (2015) sua função é possibilitar a orientação do comportamento e da comunicação entre os indivíduos, auxiliando-os na adaptação e na familiarização com o novo. Para o autor, um dos motivos pelo qual o homem pode se deparar com a falta de familiaridade é quando um objeto que se julgava abstrato surge de forma concreta diante dele. 
É plausível considerar que acontece exatamente isso com a videoaula. O professor, tradicionalmente, está acostumado a dar suas aulas presenciais, tendo o feedback do aluno em tempo real, que traz todo um dinamismo na condução de aula. Normalmente, fala-se de improviso e, salvo exceções, não há um registro do que diz para além do registro escrito. Seus possíveis vícios de linguagem, eventuais "más performances", não ficam "registrados para eternidade". O "cuspe e giz" ainda dominam.

A EAD, através das videoaulas, coloca tal roteiro em questão. Nestas, a relação entre professor e aluno é assíncrona, podendo dar-se por meio de feedback a posteriori no próprio Youtube, local onde os vídeos ficam hospedados e da onde é feito o embed para as plataformas, no caso do CEDERJ. A gravação pode ser realizada pela equipe de vídeo ou ainda, ser realizada pelo próprio professor.

Independente da situação, a dificuldade em se encarar a câmera e falar com naturalidade apareceu nas falas dos designers instrucionais (DIs) que lidam com esses professores. Segundo Cruz (2001, p.14), a videoaula impõe uma nova situação didática: há agora que se considerar

\footnotetext{
"questões de estética dos materiais didáticos, de formulação e cumprimento de objetivos pedagógicos que incorporem as condições da distância física, transformações do conteúdo aos formatos das novas mídias, de aspectos relacionados às novas rotinas de trabalho e de comunicação com os alunos".
}

Aquilo que parecia distante do professor, o ator do Telecurso, ganha concretude e lhe cobra uma posição diante da chamada à gravação. $O$ medo do estranho deve ser combatido e o não-familiar passa através das RS construídas pelo grupo de forma a se tornar familiar.

\subsubsection{Abordagem Estrutural}

Abric (2000) define a representação social como "o produto e o processo de uma atividade mental pela qual um indivíduo ou um grupo reconstitui o real com que se confronta e Ihe atribui uma significação específica" (p.64). Uma representação social possui um conteúdo e uma estrutura, composta por um núcleo central e os elementos periféricos.

O núcleo central é diretamente relacionado à história, à ideologia, sendo determinado pelo social. Ele engloba o(s) elemento(s) mais estável(is) da representação, sendo o mais resistente à mudança. Já o sistema periférico é o que permite concepções mais individualizadas e práticas diferenciadas.

Quanto às funções das representações sociais colocadas classicamente por Moscovici 
1. de saber (que permitem compreender e explicar - comunicar - a realidade) e 2. a de orientação (que orientam os comportamentos e práticas sociais e individuais), Abric(2000) acrescenta outras duas funções: 3. função identitária ("definem a identidade e permitem a proteção da especificidade dos grupos") e 4. função justificadora ("permitem a posteriori, a justificativa das tomadas de posição e dos comportamentos") (p. 29-30)

\section{PROCEDIMENTOS METODOLÓGICOS}

\subsection{Tipo de Estudo e Orientação Teórica}

Trata-se de uma pesquisa aplicada do tipo explicativo, a partir de estudo qualiquantitativo, tendo-se por base a abordagem estrutural da TRS.

\subsection{Campo de Estudo}

Nossa pesquisa se deu no âmbito da Fundação Cecierj. O universo de professores no CEDERJ, então, era de 796 que provinham de 7 universidades diferentes (CEFET/RJ, UENF, UFF, UERJ, UFRJ, UFRRJ E UNIRIO) e de 14 cursos de praticamente todas as áreas do conhecimento (Humanas, Exatas e da Terra, Biológicas, Engenharias, Sociais Aplicadas e Linguística, Letras e Artes).

\subsection{Etapas de Desenvolvimento da Pesquisa}

Duas etapas foram realizadas em três fases da pesquisa. Na primeira, chamada Motivações e Sensações, objetivou-se primeiramente apreender as motivações e expectativas que os professores participantes do Workshop Videoaula CEDERJ (WVC) possuíam em relação à gravação de videoaulas. Esta foi realizada em duas fases: em fins de 2015 e em fins de 2016. Os dados foram tratados segundo técnicas de análise de conteúdo.

A segunda etapa e terceira fase, realizada no primeiro semestre de 2016, consistiu da Análise de Representações Sociais que os professores tem de videoaula. Os dados foram obtidos através da técnica de evocação livre, cujo termo indutor era videoaula e foram tratados segundo a análise estrutural, realizada através do software Iramuteq.

Grande parte dos resultados já foram considerados quando da manutenção do projeto em sua primeira reestruturação do workshop para 2016 e novas alterações serão implementadas para a edição de 2018, diante dos resultados e interpretação finais.

\section{APRESENTAÇÃO E DISCUSSÃO DOS RESULTADOS}

\subsection{Etapa 1}

O WVC foi direcionado para os docentes, sendo realizado em dois dias nas diferentes 
universidades. No primeiro dia, entregava-se um questionário aberto para os professores. Os dados analisados são maiores que 96 (número de participantes) porque foram considerados separadamente respostas que incluíssem mais de uma unidade de registro.

\subsection{1- Motivações}

À pergunta "O que motiva sua participação?", as unidades de registro foram selecionadas e pre-categorizadas não aprioristicamente.

Tabela 1: Identificação Temática e Ocorrência

\begin{tabular}{|c|c|c|c|c|}
\hline (INDICES DAS) UNIDADES DE REGISTRO & $\begin{array}{l}\text { TEMAS/UNIDADES } \\
\text { DE SIGNIFICAÇÃO }\end{array}$ & CATEGORIA & $\boldsymbol{f}$ & $\%$ \\
\hline $\begin{array}{l}\text { CONHECER, ENTENDER, CAPACITAR, } \\
\text { ATUALIZAR, DOMINAR, APROFUNDAR }\end{array}$ & APRENDER & & & \\
\hline $\begin{array}{l}\text { MÍDIAS, ARTE, TECNOLOGIA, PELO TEMA, } \\
\text { CURIOSIDADE, DESAFIO }\end{array}$ & INTERESSE & EU & 51 & $38,93 \%$ \\
\hline APROXIMAR, INTERATIVO, CONTATO & PROXIMIDADE & & & \\
\hline $\begin{array}{l}\text { PALATÁVEL, RICO, MELHOR ENSINAR, } \\
\text { APRENDIZADO,ALUNO, INTERESSE, } \\
\text { MOTIVAÇÃO, ESCLARECIMENTO, DINAMISMO }\end{array}$ & ALUNO & ALUNO & 22 & $16,79 \%$ \\
\hline MELHORAR, ENRIQUECER, NECESSÁRIA & QUALIDADE & & & \\
\hline $\begin{array}{l}\text { PREPARAR, IMPLEMENTAR, PRODUZIR, } \\
\text { GRAVAR- MUITAS VEZES LIGADOS A } \\
\text { APRENDER }\end{array}$ & APLICAR & PRODUTO & 55 & $41,98 \%$ \\
\hline $\begin{array}{l}\text { OBRIGAÇÃO PROFISSIONAL } \\
\text { (RELEVÂNCIA IMPLICITA) }\end{array}$ & OBRIGAÇÃO PROF. & OBRIGAÇÃO & 3 & $2,29 \%$ \\
\hline TOTAL & & & 131 & $99,99 \%$ \\
\hline
\end{tabular}

Comparando os dados, fica claro que a categoria ALUNO possui uma frequência bem menor se comparada às outras duas, EU (o professor) e PRODUTO (a plataforma, a videoaula).

Tardif (2014) afirma que "as interações com os alunos (...) constituem o núcleo [do trabalho dos professores] e determinam a natureza dos procedimentos e da pedagogia".

Será que a natureza do trabalho à distância faz com que esses professores percam, em parte, o aluno como referência? Outro dado relevante é pensar que, ao menos no CEDERJ, parte dos professores funcionam apenas como conteudistas, elaborando o material online, as provas e corrigindo-as. Mas a interação com o aluno acontece muitas vezes quase que exclusivamente pelo tutor a distância e presencial. 
Por outro lado, ainda o Cederj atue na EAD, esses professores ainda atuam (ou alguns atuaram por anos) como professores presenciais. É plausível pensar que, como num clique, essa referência do aluno enquanto objeto de seu trabalho fique distante?

Verificamos em diferentes autores (Moreira,A. E Chamon, E., 2015; Alvez-Mazzotti, 2007; Velloso, A., 2010) que na medida em que os professores se afastam das séries iniciais, as RS que o professor tem de si enquanto professor se modificam. Primeiramente encontra-se como RS do professor cognições como dedicação, ou seja, diretamente relacionadas ao ALUNO. No ensino superior, são encontradas cognições como ensino e conhecimento e dificuldades e luta . Se fôssemos aplicar a "tradução" dessas cognições nas categorias encontradas, os primeiros estão diretamente relacionados a produto, e os últimos a uma questão de cunho bem pessoal/social, ao EU.

\subsubsection{Sensações}

À pergunta "Quando você pensa em gravar uma videoaula, que sentimento/sensação te ocorre?", efetuamos primeiramente uma categorização dividida em 5 temas. Estes ganharam um peso de $-3 \mathrm{a}+3$, segunda a escala de Osgood, atribuindo portanto um valor (positivo ou negativo) e uma intensidade, por parte dos pesquisadores.

Como podemos observar, $52,63 \%$ das respostas foram consideradas dentro da categoria Sensações Negativas, enquanto que somente $21,93 \%$ na categoria Sensações Positivas. Considerando a escala de Osgood, obtivemos um score de -90 a +51 , respectivamente.

Tabela 2: Atribuição Temática e Valores Osgood das sensações dos professores diante da videoaula

\begin{tabular}{ccccccc}
\hline $\begin{array}{c}\text { TEMAS } \\
\text { (UNIDADES DE SIGNIFICAÇÄO) }\end{array}$ & $\boldsymbol{f}$ & OSGOOD & CATEGORIA & $\boldsymbol{f}$ & $\boldsymbol{\%}$ & OSGOOD \\
SENTIMENTOS POSITIVOS & 25 & 51 & POSITIVA & $\mathbf{2 5}$ & $\mathbf{2 1 , 9 3}$ & 51 \\
PESO & 23 & -29 & & & & \\
PERFORMANCE & 27 & -44 & NEGATIVA & $\mathbf{6 0}$ & $\mathbf{5 2 , 6 3}$ & $\mathbf{- 9 0}$ \\
MEDOS OUTROS & 10 & -17 & & & & \\
$\begin{array}{c}\text { EXPECTATIVA } \\
\text { O QUE É PRECISO }\end{array}$ & 13 & 0 & NEUTRA & $\mathbf{1 3}$ & $\mathbf{1 1 , 4 0}$ & - \\
TOTAL & 16 & 0 & & $\mathbf{1 6}$ & $\mathbf{1 4 , 0 4}$ & - \\
\hline
\end{tabular}

Por um lado, se estamos trabalhando com um grupo profundamente interessado nas 
gravações de videoaulas é de causar estranheza um resultado tão negativo, tanto na frequência das respostas quanto na intensidade apresentada. Por outro lado, pode-se supor que, apesar da carga negativa com que os professores percebem o desafio, eles se encontram focados o bastante para lutar contra seus medos, focalizados no tema performance.

\subsection{Etapa 2: Representações Sociais de Videoaula}

A partir das 746 palavras evocadas cuja dispersão inicial era significativa (287 palavras diferentes), chegou-se a uma matriz com 84 categorias. O corpus foi analisado via Iramuteq e realizou-se a análise prototípica, obtendo-se o seguinte quadro de quatro casas:

Tabela 1: Elementos Estruturais relativos ao termo indutor "videoaula", processados por frequência e ordem média de evocação (OME)

\begin{tabular}{|c|c|c|c|c|c|}
\hline \multicolumn{3}{|c|}{ Elementos Centrais } & \multicolumn{3}{|c|}{ 1a Periferia } \\
\hline \multicolumn{3}{|c|}{ Frequência $\geq 19 / \mathrm{OME} \leq 3,4$} & \multicolumn{3}{|c|}{ Frequência $\geq 19 / \mathrm{OME} \geq 3,4$} \\
\hline & $f$ & OME & & $f$ & OME \\
\hline interação & 32 & 3,1 & ensino & 44 & 3,7 \\
\hline tecnologia & 23 & 2,9 & recursos & 26 & 4 \\
\hline ferramenta & 22 & 2,8 & dinamismo & 24 & 3,6 \\
\hline modernidade & 21 & 2,6 & atração & 24 & 3,5 \\
\hline \multirow[t]{3}{*}{ preparação } & 21 & 2,9 & alcance & 23 & 4,3 \\
\hline & & & conteúdo & 21 & 4,3 \\
\hline & & & objetividade & 20 & 4 \\
\hline \multicolumn{3}{|c|}{ Elementos de Constraste } & \multicolumn{3}{|l|}{ 2a Periferia } \\
\hline \multicolumn{3}{|c|}{ Frequência $<19 /$ OME $<3,4$} & \multicolumn{3}{|c|}{ Frequência $<19 /$ OME $>3,4$} \\
\hline & $f$ & OME & & $f$ & OME \\
\hline internet & 17 & 3,2 & dificuldade & 14 & 3,7 \\
\hline infraestrutura & 16 & 3,2 & isolamento & 12 & 3,5 \\
\hline distância & 16 & 2,8 & & & \\
\hline vídeo & 16 & 1,5 & & & \\
\hline monotonia & 16 & 3 & & & \\
\hline praticidade & 14 & 3,4 & & & \\
\hline aula & 13 & 2,1 & & & \\
\hline aprendizagem & 12 & 3,4 & & & \\
\hline ead & 12 & 3,2 & & & \\
\hline presentificação & 11 & 3,4 & & & \\
\hline imagem & 11 & 2,6 & & & \\
\hline
\end{tabular}

Considerando as justificativas colocadas para cada evocação, categorizamos as cognições encontradas em diferentes dimensões. (Em caixa alta, os possíveis elementos centrais, em negrito os elementos periféricos e em itálico, os elementos de contraste) 
- Tecnologia: TECNOLOGIA, MODERNIDADE, recursos, internet, vídeo, imagem

- Ensino: FERRAMENTA, ensino, aula, aprendizagem

- Trabalho: PREPARAÇÃO, conteúdo

- Desejo: recursos, atração, objetividade

- Dificuldade: dificuldade, infraestrutura, monotonia

- EAD: alcance, distância, ead

- Facilidade: praticidade

Quanto à carga afetiva, é possível localizarmos as cognições da seguinte forma:

- Positiva: INTERAÇÃO, TECNOLOGIA, MODERNIDADE, ensino, dinamismo, atração, alcance,objetividade, praticidade, presentificação

- Neutra: FERRAMENTA, recursos, conteúdo, internet, distância, vídeo, aula, aprendizagem, ead, imagem

- Negativa: PREPARAÇÃO,dificuldade, isolamento, infraestrutura, monotonia

A partir da interpretação desses resultados, alinhada às justificativas e também à bibliografia específica sobre videoaula, identidade docente e formação continuada, iniciamos mudanças na abordagem de captação dos professores e reestruturação do workshop.

\section{Considerações Finais (Aplicação dos Resultados ao Worshop)}

A partir das observações já da primeira fase da primeira etapa da pesquisa e alguns resultados parciais da segunda etapa, algumas modificações foram feitas já no segundo WVC.

- Primeiramente, buscou-se reforçar as motivações nos seus três focos: EU e PRODUTO, através do feedback positivo a cada progresso do professor e divulgação de depoimentos de professores satisfeitos com suas videoaulas. $\mathrm{E}$ ALUNO, quando na divulgação reforçou-se a importância dos vídeos para os alunos, dando-se publicidade à demanda discente e aos comentários positivos que os vídeos do CEDERJ possuem.

- A fim de minimizar o impacto das sensações negativas diante da exposição, esta passou a ser realizada no WCV em progressivos graus de dificuldades. A própria autogravação final, também inserida nesta edição, evoluía em diferentes exercícios que se distanciavam paulatinamente da aula presencial até chegar a aula a distância via câmera.

- Alinhada ao conceito de que a comunicação está diretamente ligada à criação, manutenção e mudança das RS, cada exercício passou a ser seguido de 
discussão em pequenos grupos. O módulo a distância fomentava maior familiaridade com diferentes formatos de videoaula, estimulando o senso crítico e também a discussão entre os pares.

Ainda, a partir das cognições encontradas, buscamos preencher as lacunas e facilitar naquilo que era visto como dificuldade pelos professores.

- Preparação e Infraestrutura: A dificuldade com a tecnologia e infraestrutura introduziu como primeiríssimo exercício a autogravação feita em dupla. Esta experiência culminava numa autogravação feita individualmente. Além do suporte tecnológico da equipe, um suporte didático também foi dado pelo setor de vídeo e os Dls, ao longo do processo, a fim de que se sentissem e fossem de fato preparados. Finalmente, se antes os professores apenas escreviam 0 conteúdo que leriam no teleprompter, agora eram responsáveis por acompanhar todo o processo de edição, sugerindo inserções de imagens, sons e reforço visual do conteúdo falado (letterings), apropriando-se de todo o processo autoral.

- Desejo: Através de exemplos da internet, buscados pelos próprios professores e posteriormente de seus próprios vídeos, percebiam como seu desejo de atratividade e objetividade podiam se tornar realidade através dos recursos disponíveis, evitando assim qualquer monotonia na videoaula.

Com a finalização da análise dos dados e consequente interpretação, uma reestruturação do WVC está atualmente em elaboração para a nova edição de 2018. Nesta, pretendemos ainda focar num aspecto que apareceu com uma certa discrepância. A cognição interação, aparentemente o mais significativo dos elementos centrais, também aparece enquanto isolamento, na segunda periferia. Ou seja, para a grande maioria dos professores, a videoaula é um elemento de interação entre professor e alunos, conceito este que pode ser colocado inclusive em questão já que se trata de uma comunicação unidirecional em princípio e de um feedback, quando existente, assíncrono. Para um grupo menor, mas significante, a videoaula, na verdade, é instrumento de isolamento entre aluno e professor. Vemos aí a necessidade de uma discussão mais aprofundada entre interação e interatividade, conceitos que os docentes parecem confundir. E pretendemos, assim, trazer possibilidades de recursos interativos na próxima edição do workshop. Também objetivamos esse ano a criação de um espaço para debate continuado dos professores sobre o tema.

Tais proposições são consoantes com o entendimento da TRS, de que assim como as representações sociais influenciam as práticas, o inverso, incluindo aí maior conversação sobre o objeto em questão, também é correto. 


\section{Principais Referências}

ABRIC, J-C. A abordagem estrutural das representações sociais. In: Moreira, A.S.; Oliveira, D.C. (Orgs.) Estudos interdisciplinares de representação social. Goiânia: AB, 2000.

ALVES-MAZZOTTI, A. Representações da identidade docente: uma contribuição para a formulação de políticas. Ensaio, 01 December 2007, Vol.15(57), pp.579-59.

BARDIN, L. Análise de conteúdo. Lisboa: Edições 70, 1977.

BREAKWELL, G.M., Social Representation and Social Identity, Papers on Social Representations, Vol. 2, 1-20, 1993.

CRUZ, D. M. O professor midiático: a formação docente para a educação a distância no ambiente virtual da videoconferência. (Doutorado em Engenharia de Produção) Programa de Pós-Graduação em Engenharia de Produção, Universidade Federal de Santa Catarina. Florianópolis, 2001.

JODELET, D. Representações Sociais: um domínio em expansão. In: JODELET, D. As Representações Sociais. Rio de Janeiro: UERJ. 2001.

MOLINER, P. A two-dimensional model of social representations. European Journal of Social Psychology, 25(1), 27-40.1995.

MOSCOVICl, S. Representações sociais: investigações em psicologia social. Petrópolis: Vozes, 2015.

PERRENOUD, P. Avaliação: da excelência à regulação das aprendizagens, entre duas lógicas. Porto Alegre: Artmed, 1999.

TARDIF, M. Saberes docentes e formação profissional Petrópolis: Vozes, 2014.

VELLOSO, A. Representações sociais e a construção da identidade profissional de professor (Doutorado em Educação,Gestão e Difusão em Biociências). Instituto de Bioquímica Médica Leopoldo De Meis, UFRJ. Rio de Janeiro. 2009. 